OPEN ACCESS

Edited by:

Amre Nouh,

Hartford Hospital and University of

Connecticut, USA

Reviewed by:

Olimpia Mihaela Carbunar,

Baptist Hospital, USA

Christoph Stretz,

Hartford Hospital and University of

Connecticut, USA

Mohammed Arif Hussain,

Hartford Hospital, USA

*Correspondence:

Judith Bellapart

judithbellapart@gmail.com

Specialty section:

This article was submitted to

Neurocritical and Neurohospitalist

Care,

a section of the journal

Frontiers in Neurology

Received: 24 September 2015

Accepted: 14 January 2016

Published: 02 February 2016

Citation:

Bellapart J, Cuthbertson K,

Dunster K, Diab S, Platts DG,

Raffel OC, Gabrielian L, Barnett A,

Paratz J, Boots $R$ and Fraser JF

(2016) Cerebral Microcirculation during Experimental

Normovolaemic Anemia.

Front. Neurol. 7:6.

doi: 10.3389/fneur.2016.00006

\title{
Cerebral Microcirculation during Experimental Normovolaemic Anemia
}

\author{
Judith Bellapart ${ }^{1 *}$, Kylie Cuthbertson ${ }^{1}$, Kimble Dunster ${ }^{2,3}$, Sara Diab ${ }^{2,3}$, David G. Platts ${ }^{3,4}$, \\ O. Christopher Raffe ${ }^{3,4}$, Levon Gabrielian ${ }^{5}$, Adrian Barnett ${ }^{3,6}$, Jenifer Paratz ${ }^{1}$, Rob Boots ${ }^{1}$ \\ and John F. Fraser,2,3,7
}

'Department of Intensive Care, Royal Brisbane and Women's Hospital, Herston, QLD, Australia, ${ }^{2}$ Critical Care Research Group, University of Queensland, St Lucia, QLD, Australia, ${ }^{3}$ Medical Engineering Research Facility, Queensland University of Technology, Brisbane, QLD, Australia, ${ }^{4}$ Department of Cardiology, The Prince Charles Hospital, Chermside, QLD, Australia, ${ }^{5}$ Medical Research Centre, Medical School, University of South Australia, Adelaide, SA, Australia, ${ }^{6}$ School of Public Health and Social Work, Institute of Health and Biomedical Innovation, Queensland University of Technology, Brisbane, QLD, Australia, ${ }^{7}$ Department of Intensive Care, The Prince Charles Hospital, Chermside, QLD, Australia

Anemia is accepted among critically ill patients as an alternative to elective blood transfusion. This practice has been extrapolated to head injury patients with only one study comparing the effects of mild anemia on neurological outcome. There are no studies quantifying microcirculation during anemia. Experimental studies suggest that anemia leads to cerebral hypoxia and increased rates of infarction, but the lack of clinical equipoise, when testing the cerebral effects of transfusion among critically injured patients, supports the need of experimental studies. The aim of this study was to quantify cerebral microcirculation and the potential presence of axonal damage in an experimental model exposed to normovolaemic anemia, with the intention of describing possible limitations within management practices in critically ill patients. Under non-recovered anesthesia, six Merino sheep were instrumented using an intracardiac transeptal catheter to inject coded microspheres into the left atrium to ensure systemic and non-chaotic distribution. Cytometric analyses quantified cerebral microcirculation at specific regions of the brain. Amyloid precursor protein staining was used as an indicator of axonal damage. Animals were exposed to normovolaemic anemia by blood extractions from the indwelling arterial catheter with simultaneous fluid replacement through a venous central catheter. Simultaneous data recording from cerebral tissue oxygenation, intracranial pressure, and cardiac output was monitored. A regression model was used to examine the effects of anemia on microcirculation with a mixed model to control for repeated measures. Homogeneous and normal cerebral microcirculation with no evidence of axonal damage was present in all cerebral regions, with no temporal variability, concluding that acute normovolaemic anemia does not result in short-term effects on cerebral microcirculation in the ovine brain. 


\section{INTRODUCTION}

Anemia and its pathophysiological implications have been investigated in recent years (1). The deleterious effects of blood transfusions have been well documented (2-4). Since the TRICC Trial $(5)$, evidence based guidelines $(6,7)$ have influenced the use of blood transfusions, particularly in critically ill patients. However, a post hoc subgroup analysis of head injury patients from the TRICC trial (8) assessed the effects of restrictive transfusion strategies with hemoglobin concentrations maintained between 7.0 and $9.0 \mathrm{~g} / \mathrm{dL}$ compared to the maintenance of hemoglobin concentrations between 10.0 and $12.0 \mathrm{~g} / \mathrm{dL}$ on neurological outcome at 60 days post-injury. In that study, the authors found a significantly higher incidence of blood transfusions in the liberal group, with no differences in the ICU or 60-day mortality, length of stay, or organ failures. However, the direct effects of anemia on neurological outcomes were not assessed. It is still controversial whether anemia worsens brain injury (9-11). A recent study (12) examined the associations between the management of acute head injury patients with a restrictive versus a liberal transfusion threshold and the administration of erythropoietin with neurological outcomes at 6 months as the primary endpoint. No difference in neurological outcome was demonstrated with either intervention, with the lowest hemoglobin being $10 \mathrm{~g} / \mathrm{dL}$. However, several studies (13-18) have raised concerns regarding the safety of tolerating anemia in the setting of acute head injury. These studies showed that a sustained hemoglobin concentration of $7 \mathrm{~g} / \mathrm{dL}$ correlated with secondary neurological injury from cerebral tissue hypoxia (13), with blood transfusion significantly increasing the partial pressure of cerebral tissue oxygenation $\left(\mathrm{PTiO}_{2}\right)$ independently of cerebral perfusion pressure $(14,15)$. In addition, critical levels of $\mathrm{PTiO}_{2}(<15 \mathrm{mmHg})$ are correlated with a significant increase in the incidence of stroke and mortality $(17-20)$. As a result of cerebral tissue ischemia, cerebral microdialysis markers, such as lactate/pyruvate ratio, glutamate, and glycerol, rise as a reflection of altered cellular metabolism (21, 22). In the absence of clinically available measures of cerebral microcirculation, transfusion thresholds in head injury patients may be better determined by physiological markers of cerebral ischemia and hypoperfusion rather than those recommended in more general critical care case mix where only mortality outcomes are assessed (22).

In light of this controversy, this novel study aimed to directly quantify regional microvascular blood flow (RMBF) using cytometric counting of color-coded microspheres with the potential neurological injury assessed using amyloid precursor protein (APP) staining of brain tissue of sheep exposed to normovolemic anemia.

\section{MATERIALS AND METHODS}

\section{Animal Care and Preparation}

All experimental procedures were approved by the Animal Ethics Committee of the Queensland University of Technology and University of Queensland Committee and complied with local guidelines. Sheep were selected as the preferred animal model because of their cerebral anatomical similarities with humans, specifically within the gyrencephalic structure, allowing better examination of gray-white matter. In addition, the hemoglobin dissociation curve in sheep is comparable to that of human with a considerable amount of experimental studies in ovine neurosciences. A triple lumen central line (Cook Medical INC., QLD, Australia) and two 16-Fr introducer sheaths were placed in the right internal jugular (RIJ) vein in a convenience sample of six Merino sheep wethers weighing $65 \pm 6.01 \mathrm{~kg}$. Via the central line, the sheep were placed under general anesthesia with an initial bolus of $5 \mathrm{mg} / \mathrm{kg}$ ketamine and a maintenance infusion between 0.5 and $1 \mathrm{mg} / \mathrm{kg} / \mathrm{h}$. Sedation was achieved with a combined infusion of midazolam $(0.5 \mathrm{mg} / \mathrm{kg} / \mathrm{h})$, fentanyl $(10 \mathrm{mcg} / \mathrm{kg} / \mathrm{h})$, and alfaxalone $(6 \mathrm{mg} / \mathrm{kg} / \mathrm{h})$. This is a common veterinarian anesthetic regimen that has stable cardiovascular effects. Hydration was maintained with an infusion of Hartmann's solution at a rate up to $2 \mathrm{~mL} / \mathrm{kg} / \mathrm{h}$ titrated to a central venous pressure (CVP) of 6-10 mmHg. Cardiovascular monitoring included cardiac output and vascular resistances via a Swan-Ganz catheter, as in previous models (23). A 5-Fr umbilical vessel catheter (Argyle, Tyco HealthCare, Mansfield, MA, USA) was placed in the right femoral artery to allow for blood withdrawal at a rate of $10 \mathrm{~mL} /$ min. Orotracheal intubation was performed with a $10-\mathrm{mm}$ endotracheal tube (SIMS Portex, UK). Sheep were ventilated at 12 breaths per minute with tidal volumes of $8 \mathrm{~mL} / \mathrm{kg}$ and $5 \mathrm{~cm}$ $\mathrm{H}_{2} \mathrm{O}$ of PEEP with an initial $\mathrm{FiO}_{2}$ of 1.0. The $\mathrm{FiO}_{2}$ and respiratory rate were titrated to maintain a partial pressure of oxygen $\left(\mathrm{PaO}_{2}\right)$ of $>95 \mathrm{mmHg}$ and normocapnia. PEEP was maintained at $5 \mathrm{~cm}$ $\mathrm{H}_{2} \mathrm{O}$ to minimize de-recruitment and was not increased during the study, as this level of PEEP is known to have no effects on cerebral perfusion pressures (24). Neuromonitoring instrumentation included a partial pressure of tissue oxygenation $\left(\mathrm{PTiO}_{2}\right)$ probe (Licox, Oxford Optronics, Ltd, Oxford, UK) and an intracranial pressure (ICP) monitor, inserted via a mini-craniectomy at the left and right fronto-parietal regions, respectively. CPP was derived using the clinical algorithm: $\mathrm{CPP}=$ mean systemic arterial blood pressure (MAP)-ICP, with MAP being measured at the level of the heart.

To avoid self-transfusion from the ovine spleen $(25,26)$, a ligation of the splenic artery was performed through a skin incision parallel to the distal end of the last rib on the left side followed by blunt dissection through the serratus and oblique abdominal muscles. The splenic artery and vein were identified, the artery ligated followed by injection of adrenaline $(0.025 \mathrm{~mL}$ of 1:10,000 dilutions) directly into the spleen parenchyma and a 60 -s waiting period to allow for spleen contraction and the return of the sequestered blood into the systemic circulation.

\section{Normovolaemic Anemia Model}

Acute normovolaemic anemia was achieved by sequential blood extractions from the indwelling arterial catheter performed simultaneously with isovolaemic saline infusions. The aim was to achieve a $30 \%$ reduction of baseline hemoglobin to reproduce the fall in hemoglobin concentration that was achieved in the TRICC trial. The targeted hemoglobin was monitored using cardiac index, blood pressure, systemic vascular resistances, and arterial blood gas sampling to ensure stable and normal lactate levels, every $15 \mathrm{~min}$. 


\section{Protocol for Transeptal Catheterization and Injection of Microspheres}

Following anesthesia, a transeptal catheter was inserted into the left atrium (LA) under intracardiac echocardiography (ICE) surveillance. Two 11-Fr Terumo sheaths located in the RIJ allowed for the insertion of the intracardiac ultrasound probe (Acuson AcuNav $^{\mathrm{TM}}$ probe, California ${ }^{\circledR}$ ) and the transeptal catheter (Mullins TS introducer, Medtronic ${ }^{\circledR}$ ). Echocardiography images were obtained using an Acuson Sequoia C512 scanner (Siemens, CA, USA). Transeptal puncture and insertion of a pigtail catheter into the LA followed previously described methods (27).

\section{Protocol for Microsphere Injection}

Randomly assigned color-coded microspheres (E-Z TRAC; Interactive Medical Technology, Los Angeles, CA, USA) were injected hourly via the LA pigtail catheter using the following protocol. Six different colors (purple low, purple high, pink high, yellow high, coral low, and coral high) were used as per the manufacturer's recommendations. For each injection, a thoroughly mixed vial of one color of microspheres containing 5 million spheres in $0.8 \mathrm{~mL}$ volume was used. This microsphere density is recommended by the manufacturer and does not cause microvascular plugging or occlusion (23). At $30 \mathrm{~s}$ following the initiation of the blood withdrawal with a pump rate of $10 \mathrm{~mL} / \mathrm{min}$, a fast injection of the microspheres followed by a $10 \mathrm{~mL}$ saline flush over $10 \mathrm{~s}$ was performed. The withdrawal pump was turned off after 2 min of use, and Tween 80 reagent was used to clear the arterial catheter and dilute the microspheres.

\section{Aspects of the Injection of Color-Coded Microspheres}

Approximately, five million color-coded spheres of one color were injected at each hour with the color of the microspheres randomly assigned at each injection time, to minimize selection biases and to enable the quantification of flow at each defined time points. Each sheep had a different microsphere color injected at defined time points to assess temporal changes in RMBF by anatomical area. As per the manufacturer's recommendations, the microspheres were maintained at room temperature, were not exposed to sunlight, heat, or vibration, and were mixed manually to minimize foaming and avoid non-uniform concentrations of microspheres throughout each injection.

\section{Euthanasia and Post-Mortem Tissue Manipulation}

After $5 \mathrm{~h}$ of continuous monitoring and microsphere injection, sheep were euthanized under non-recovered anesthesia with a bolus injection of $0.5 \mathrm{~mL} / \mathrm{kg}$ of sodium pentobarbitone. After confirmation of death, the brain was harvested by craniotomy, weighed, and then fixed in $10 \%$ formalin for 3 weeks.

\section{Brain Harvesting Technique}

Brains were harvested using a deep incision of the skin and underlying tissue planes between the first and second occipital vertebral body with the intention of sectioning the spinal cord at that level. A round reciprocating saw was used to create a wide bitemporal bone incision. Rectangular bone sections of $\sim 5 \mathrm{~cm}$ were made anteriorly to the bitemporal incision to the frontal sinuses. These bone sections were removed with retractors with simultaneous dissection of the dura. Once the brain was fully exposed, the olfactory bulbs, optic chiasm, tentorium, and cranial nerves were sectioned to liberate the brain from the cranium.

\section{Tissue Sampling Model}

A novel design for tissue sampling was developed to capture the specific anatomical regions of interest (Figure 1A). After creating 5 -mm brain blocks, $0.4 \mathrm{~g}$ cone samples were extracted from the hemispheres (AR corresponding to right parietal cortex, BR corresponding to right temporal cortex, AL corresponding to left parietal cortex, and BL corresponding to left temporal cortex), basal ganglia (C), and medulla (D). Adjacent tissue blocks were assigned for both cytometric and histological analyzes. This novel design allowed us to directly quantify axonal damage and RMBF in specific anatomical regions, which could be compared between subjects with different brain sizes.

Samples of skin, gut, kidney, spleen, and heart were harvested to demonstrate the systemic distribution of the microspheres. The

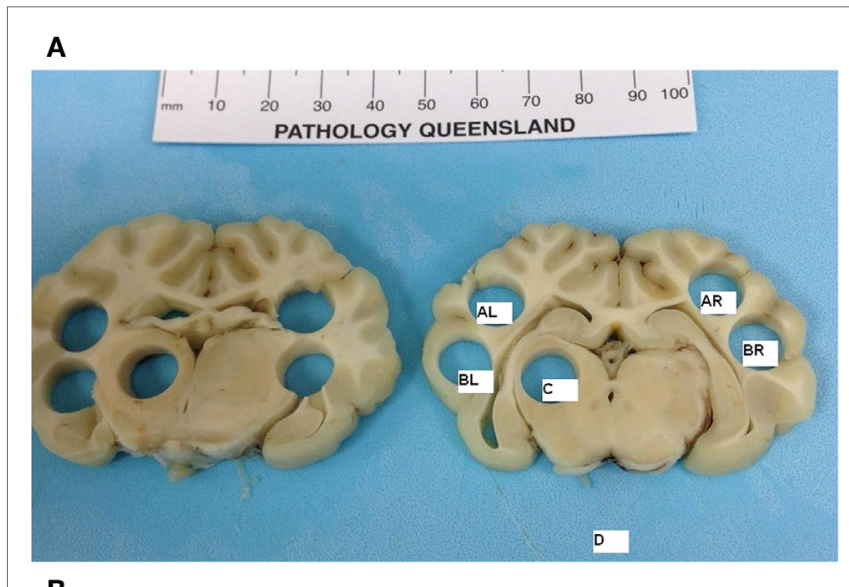

B

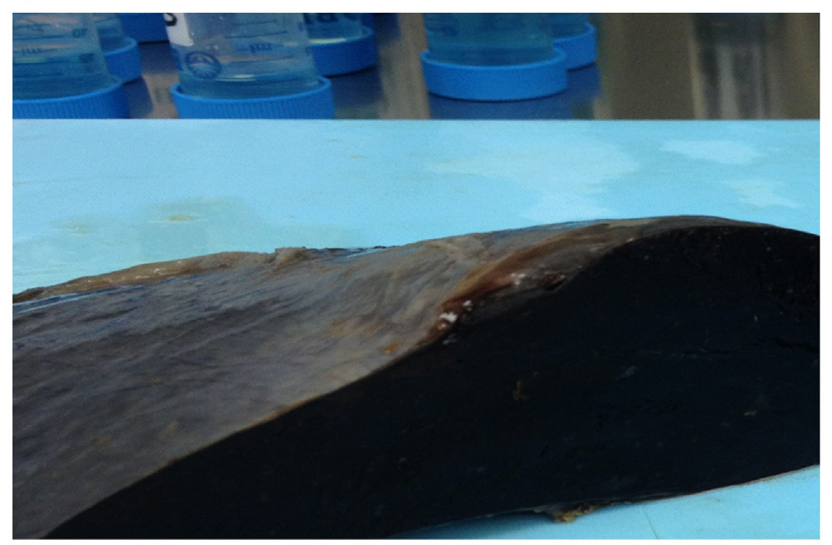

FIGURE 1 | (A) Cone post-mortem and post-fixation samples representing the anatomical regions of interest. AL, left parietal; BL, left temporal; C, left-sided basal ganglia; AR, right parietal; BR, right temporal, D, Medulla. (B) Post-mortem spleen showing macroscopic evidence of infarct as a result of successful splenic artery ligation. 
spleen was sampled to demonstrate splenic infarct due to successful arterial spleen ligation and the absence of microspheres (Figure 1B).

\section{Quantification of Microvascular Blood Flow}

Cytometric counts of the microspheres were performed using a validated technique $(23,28-30)$. Cytometric count of microspheres allows the calculation of RMBF in each particular organ through a process that includes the specific microspheres concentration injected into the systemic circulation at each time point and the amount of spheres in a reference sample of arterial blood, known also as the "reference sample of blood", extracted also at each time point. The reference sample was an arterial blood sample withdrawn at a known rate over a fixed period of time (31). RMBF was the proportion of microspheres trapped in the targeted tissue in relation to the total quantity of spheres per milliliter of blood per minute of the reference sample and was calculated using the following algorithm (32):

$$
\begin{aligned}
\operatorname{RMBF}(\mathrm{mL} / \mathrm{min} / \mathrm{g})= & (\text { Total tissue spheres }) / \\
& {[(\text { Tissue weight, } \mathrm{g}) \times} \\
& (\text { Reference Spheres } / \mathrm{mL} / \mathrm{min})]
\end{aligned}
$$

This cytometric analysis was performed at Interactive Medical Technology (IMT), Los Angeles, CA, USA.

\section{Immunohistochemistry Processing}

Immunohistochemistry analysis was performed at the neuropathology laboratory, Royal Brisbane and Women's Hospital, QLD, Australia, using a Leica Novolink Polymer Detection Systems Kit (Leica Microsystems Pty Ltd., North Ryde, 2113 Australia) as per the manufacturer's instructions. Paraffin was removed from the sections through a series of xylene immersions and re-hydrations. Antigen retrieval was carried out using Leica BOND ER1 solution. Endogenous peroxidase was neutralized. Sections were incubated with a protein block. The primary antiserum made up in Leica BOND Antibody Diluent was applied to the sections.

\section{Immunohistochemistry and Hematoxylin-Eosin Scoring and Interpretation}

Immunohistochemistry analysis was applied to the sheep brains for the baseline presence and location of APP antibodies. APP antibody staining was used because it is considered to be a very early marker of neuronal damage (33) and this study had a short follow-up period ( $4 \mathrm{~h}$ post intervention). A grading system measuring the presence of APP was developed and structured into three qualitative categories dependent on the severity of injury: Mild Injury: focal contusion with APP labeling limited to the site of the injury or focal APP labeling; Moderate Injury: a pattern of APP staining greater than one hemisphere, greater than half a hemisphere, or less than half a hemisphere; and Severe Injury: the presence of diffuse staining sub-classified as either diffuse vascular injury, diffuse axonal injury with macroscopic hemorrhage, diffuse axonal injury with microscopic hemorrhage/tissue tears, or diffuse axonal injury only (34). For each animal, samples were taken from each brain anatomical region of interest for both cytometric counts of RMBF and immunohistochemistry.

\section{Statistical Analysis RMBF Analysis}

Regional microvascular blood flow was measured at baseline with no anemia (corresponding to time zero - T0) and at four follow-up times following the induction of anemia (T1-T4 corresponding to first to the fourth hour post intervention). A repeated-measure mixed regression model was used to examine differences in RMBF associated with anemia, and a mixed model with a random intercept was used for each sheep to control for repeated results from the same sheep.

To examine the variability in RMBF, all results were plotted using box-plots. We also calculated the percentage of the total variation in the mixed models due to the between-sheep variability. A high percentage (above 50\%) indicated that the variance in RMBF was due to differences between sheep, whereas a lower percentage indicated that the differences between sheep were small. The analysis was performed used $\mathrm{R}$ software version 3.0.2.

\section{RESULTS}

Despite a fall in hemoglobin to levels between 6 and $7 \mathrm{~g} / \mathrm{dL}$ (a 30\% of the baseline hemoglobin in each animal) with normovolaemia, cerebral RMBF throughout all anatomical areas of interest was maintained in a physiological range after correction to conventional units $(\mathrm{mL} / 100 \mathrm{~g} / \mathrm{min})$ during the $4 \mathrm{~h}$ of studying time. However, subject number 3 had a significant increase in RMBF at $4 \mathrm{~h}$ (T4) with otherwise similar RMBF values at earlier time points (Figure 2A). This was due to the reference blood sample containing significantly fewer microspheres due to a most likely, defective withdrawal pump rate, leading to an overestimation of RMBF.

Box-plots (Figure 2B) show changes in RMBF variability over time. The heights of the boxes and their means are similar, suggesting that the values were maintained within similar ranges. The dots indicate the presence of some outliers.

The effect of anemia on RMBF during the $4 \mathrm{~h}$ of study time is presented in Table 1. Anemia decreased the RMBF in the kidneys. The highest ratio of $97 \%$ was observed in the skin. The between-sheep variability seen in Figures 2A,B depended mainly on the outlier values of subject 6 .

The cardiovascular responses to acute normovolaemic anemia are presented in Table 2. For the majority of animals, the physiological response to acute anemia was a reduction in cardiac output and an increase in the systemic vascular resistances. Vascular resistances were not available for subject 1 due to a calibration error.

The cerebral $\mathrm{PTiO}_{2}, \mathrm{CPP}$, and $\mathrm{CO}$ responses to acute anemia are described in Table 2. For the majority of subjects, temporal reductions in cerebral perfusion pressure and cerebral $\mathrm{PTiO}_{2}$ were observed during anemia. Despite these changes in regional 

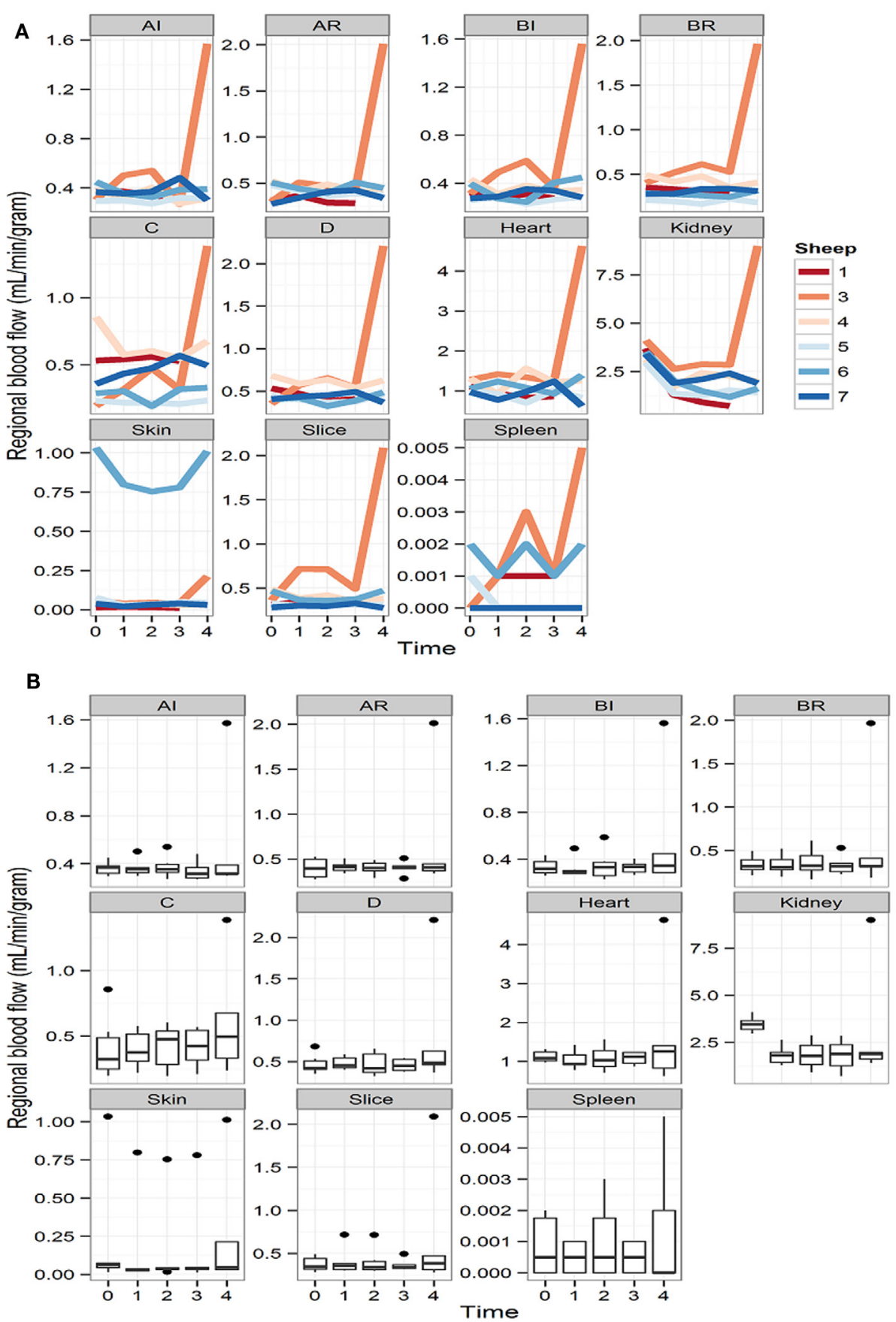

FIGURE 2 | (A) Representation of the regional blood flow for each subject over time at each particular region of interest and other extra-cranial tissues. Time is represented as T0 (baseline time or time prior to intervention); T1 (first hour post intervention); T2 (second hour post intervention); T3 (third hour post intervention), and T4 (fourth hour post intervention). (B) RMBF means at each time point of all subjects, showing stable, homogeneous, and sustained RMBF during anemia. Time is represented as T0 (baseline time or time prior to intervention); T1 (first hour post intervention); T2 (second hour post intervention); T3 (third hour post intervention); and T4 (fourth hour post intervention).

cerebral oxygenation, both histology and immunohistochemistry were consistent with normal neural tissue, represented by a normal hematoxylin-eosin and APP staining, respectively (Table 3), with only isolated areas of petechial hemorrhage (Figure 3).

\section{DISCUSSION}

This study demonstrates the maintenance of stable cerebral microcirculation in Merino sheep during and after $4 \mathrm{~h}$ of sustained normovolaemic anemia. After the achievement of a 
TABLE 1 | Effect of anemia on RMBF by anatomical regions.

\begin{tabular}{lrrrrr}
\hline Tissue & Mean & Lower & Upper & $\boldsymbol{p}$-value & Ratio \\
\hline Al & 0.045 & -0.166 & 0.256 & 0.676 & 7 \\
BI & 0.053 & -0.150 & 0.258 & 0.609 & 19 \\
AR & 0.075 & -0.203 & 0.354 & 0.6 & 3 \\
BR & 0.067 & -0.186 & 0.322 & 0.601 & 29 \\
C & 0.050 & -0.148 & 0.247 & 0.619 & 28 \\
D & 0.077 & -0.221 & 0.375 & 0.613 & 11 \\
Slice & 0.082 & -0.189 & 0.353 & 0.553 & 26 \\
Skin & -0.042 & -0.101 & 0.016 & 0.164 & 97 \\
Spleen & 0.000 & -0.001 & 0.001 & 0.989 & 42 \\
Kidney & -1.371 & -2.505 & -0.229 & 0.0248 & 30 \\
Heart & 0.089 & -0.508 & 0.690 & 0.769 & 17 \\
\hline
\end{tabular}

$30 \%$ reduction of baseline hemoglobin, as in the TRICC trial, despite a reduction in cardiac output and an increase in vascular resistances, RMBF remained unchanged in both intra- and intersubject comparisons. This observation suggests that despite the cardiovascular impact of anemia, cerebral autoregulation in an otherwise intact brain is perhaps the mechanism involved in the preservation of microcirculation throughout different anatomical regions; however, specific measurement of cerebral autoregulation was not the focus of this study.

Normovolaemic anemia alone in the short term does not appear to have objective effect on brain tissue histo-anatomy. However, cerebral microcirculation and cerebral autoregulation

TABLE 2 | Cardiovascular and cerebral oximetry response to normovolemic anemia.

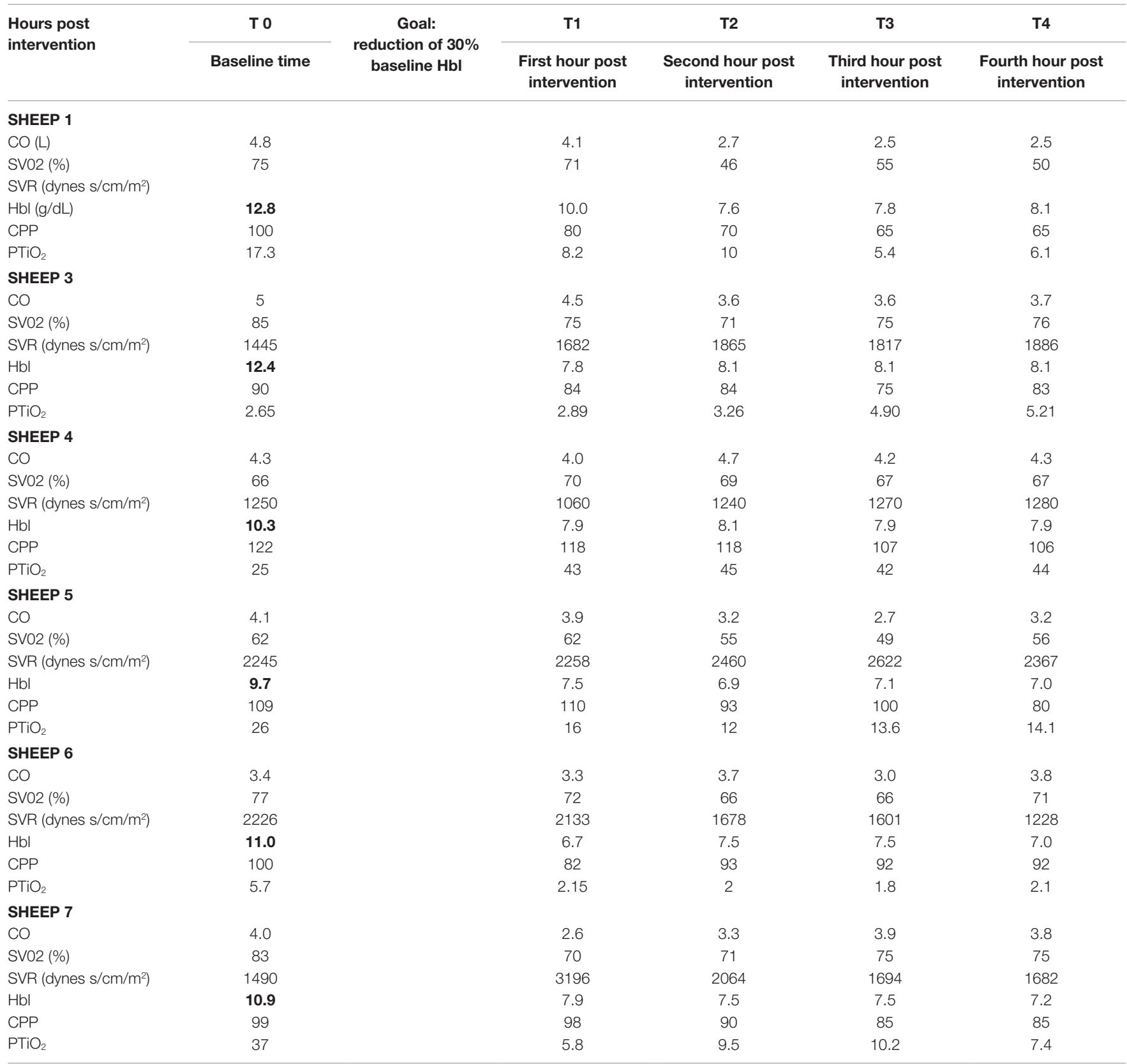

Bold values represent the baseline hemoglobin as a way to magnify the successful achievement of anaemia maintained in the following cut off time-points. 
TABLE 3 | APP staining score for all anatomical regions of interest and subjects.

\begin{tabular}{|c|c|c|c|}
\hline $\begin{array}{l}\text { Subject } \\
\text { number }\end{array}$ & $\begin{array}{l}\text { Region of } \\
\text { interest }\end{array}$ & H\&E staining & $\begin{array}{c}\text { APP } \\
\text { staining }\end{array}$ \\
\hline \multirow[t]{6}{*}{ Sheep 01} & $\mathrm{AL}$ & Normal & 0 \\
\hline & AR & Normal & 1 \\
\hline & $\mathrm{BL}$ & Normal & 0 \\
\hline & $\mathrm{BR}$ & Microglial activation & 2 \\
\hline & C & Focal hemorrhagic necrosis & 2 \\
\hline & $\mathrm{D}$ & Normal & 0 \\
\hline \multirow[t]{6}{*}{ Sheep 03} & $\mathrm{AL}$ & Normal & 0 \\
\hline & $A R$ & Normal & 0 \\
\hline & $\mathrm{BL}$ & Normal & 0 \\
\hline & $\mathrm{BR}$ & Normal & 0 \\
\hline & C & Normal & 0 \\
\hline & $\mathrm{D}$ & $\begin{array}{l}\text { Small perivascular petechial } \\
\text { hemorrhage }\end{array}$ & 1 \\
\hline \multirow[t]{6}{*}{ Sheep 04} & $\mathrm{AL}$ & Normal & 0 \\
\hline & $A R$ & Normal & 0 \\
\hline & $\mathrm{BL}$ & Normal & 0 \\
\hline & $\mathrm{BR}$ & $\begin{array}{l}\text { Small perivascular petechial } \\
\text { hemorrhage at edge, artifact? }\end{array}$ & 0 \\
\hline & C & $\begin{array}{l}\text { Small perivascular petechial } \\
\text { hemorrhage at edge, artifact? }\end{array}$ & 0 \\
\hline & $\mathrm{D}$ & Normal & 0 \\
\hline \multirow[t]{6}{*}{ Sheep 05} & $A L$ & Normal & 0 \\
\hline & $A R$ & Normal & 0 \\
\hline & $\mathrm{BL}$ & Normal & 0 \\
\hline & $\mathrm{BR}$ & Normal & 0.5 \\
\hline & $\mathrm{C}$ & Normal & 0 \\
\hline & $\mathrm{D}$ & Normal & 0 \\
\hline \multirow[t]{6}{*}{ Sheep 06} & $\mathrm{AL}$ & $\begin{array}{l}\text { Localized focus of acute meningitis } \\
\text { and SAH in depth of sulcus }\end{array}$ & 0 \\
\hline & $A R$ & Normal & 0 \\
\hline & $\mathrm{BL}$ & Normal & 0 \\
\hline & $\mathrm{BR}$ & Normal & 0 \\
\hline & C & Focal hemorrhage near deep gray nuclei & 2 \\
\hline & $\mathrm{D}$ & Normal & 0 \\
\hline \multirow[t]{6}{*}{ Sheep 07} & $A L$ & Normal & 0 \\
\hline & $A R$ & Normal & 0 \\
\hline & $\mathrm{BL}$ & Normal & 0 \\
\hline & $\mathrm{BR}$ & Normal & 0 \\
\hline & C & Normal & 0 \\
\hline & $\mathrm{D}$ & Normal & 0 \\
\hline
\end{tabular}

have heterogeneous behaviors that can lead to perfusion mismatch. This characteristic may be magnified in situations where normal perfusion is compromised, such as in head injury and hemorrhagic shock $(35,36)$ or in pre-morbid conditions affecting the cardiovascular physiology, such as hypertension, vascular diseases, or diabetes. Brain blood flow varies according to the anatomical regional (37) and it remains unclear if this represents a phylogenic remnant or a response to metabolic demands. While many factors have been considered to influence microcirculation (38), the optimal level of hemoglobin during acute head injury remains controversial. In this study, we demonstrate that during acute normovolaemic anemia to levels of hemoglobin of $6 \mathrm{~g} / \mathrm{dL}$, RMBF remains normal and unchanged over $4 \mathrm{~h}$. The results of our study are in concordance with the most recent study (12) in acute head injury patients;

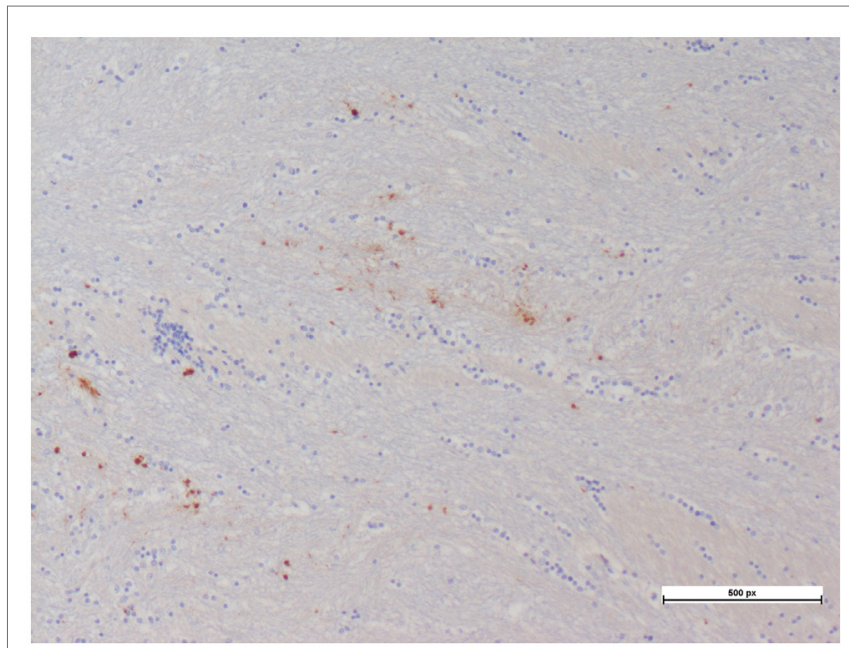

FIGURE 3 | Petechial hemorrhage with minimal hematoxylin-eosin and APP staining seen in a cerebral tissue sample.

however, that study was compromised by the concomitant use of erythropoietin and a small sample size.

The experimental strategy used for the direct measurement of RBMF and tissue sampling in this study has proven to be feasible. Quantification of RMBF in specific brain regions allows for intraand inter-subject comparisons and is a significant improvement on previous approaches using predefined brain thickness sectioning (27). In this study, RMBF in the specific regions of interest shared the same values when a predefined brain slicing technique was used. In addition, with both strategies, RMBF values were within normal ranges.

Limitations of this study are inherent to the experimental nature of the study. Regional microcirculatory blood flow cytometric count in targeted regions of the brain, before and after an insult is not a feasible method in humans. Cerebral cytometric count of microspheres is mainly an experimental concept although it shares the same physical principle of flow cytometry extensively applied in diagnostic medicine (39). Another limitation of this study refers to the short study time; however, the primary intention of this study design was to focus on the direct effect of acute normovolemic anemia in cerebral RMBF at specific anatomical regions of interest, not the long-term effects of anemia in cerebral physiology, let alone neurological outcomes. Finally, this study was applied in healthy subjects as the investigators intended to exclude all possible confounders to the direct effect of short-term anemia in cerebral microcirculatory dynamics. It is plausible to presuppose that the same degree of anaemia in pre-morbid subjects could have led to different RMBF distribution; however, this was not the main aim of the study; but to establish the direct effect of anemia in cerebral microcirculation as a preliminary model to compare with future head injury models.

This study achieved predefined aims and followed a rigorous methodology, demonstrating that short-term normovolemic anemia does not impair cerebral RMBF at specific anatomical regions, a model not feasible in the clinical arena, as an adjunct data to future head injury studies. 


\section{CONCLUSION}

Acute normovolaemic anemia replicating a restrictive transfusion strategy in ovine models without head injury does not impair cerebral microcirculation or induce axonal damage.

\section{AUTHOR CONTRIBUTIONS}

Primary roles: JB, Study design, surgical procedures and data collection, data interpretation, and manuscript preparation. KC, Histopathology analysis. KD, Laboratory support and

\section{REFERENCES}

1. Silverberg DS, Iaina A, Wexler D, Blum M. The pathological consequences of anaemia. Clin Lab Haematol (2001) 23:1-6. doi:10.1046/j.1365-2257.2001.00352.x

2. Salpeter SR, Buckley JS, Chatterjee S. Impact of more restrictive blood transfusion strategies on clinical outcomes: a meta-analysis and systematic review. Am J Med (2014) 127:124.e-31.e. doi:10.1016/j.amjmed.2013.09.017

3. Murphy GJ, Reeves BC, Rogers CA, Rizvi SI, Culliford L, Aangelini GD. Increased mortality, postoperative morbidity, and cost after red blood cell transfusion in patients having cardiac surgery. Circulation (2007) 116:2544-52. doi:10.1161/CIRCULATIONAHA.107.698977

4. Kumar P, Thapliyal R, Coshic P, Chatterjee K. Retrospective evaluation of adverse transfusion reactions following blood product transfusion from a tertiary care hospital: a preliminary step towards hemovigilance. Asian J Transfus Sci (2013) 7:109-15. doi:10.4103/0973-6247.115564

5. Hebert PC, Wells G, Blajchman MA, Marshal J, Martin C, Pagliarello G, et al. A multicenter, randomized, controlled clinical trial of transfusion requirements in critical care. Transfusion requirements in critical care investigators, Canadian critical care trials group. N Engl J Med (1999) 340:409-17. doi:10.1056/NEJM199902113400601

6. Carson JL, Grossman BJ, Kleinman S, Tinmouth AT, Marques MB, Fung MK, et al. Red blood cell transfusion: a clinical practice guideline from the $\mathrm{AABB}^{*}$. Ann Intern Med (2012) 157:49-58. doi:10.7326/ 0003-4819-157-1-201206190-00429

7. Carson JL, Carless PA, Hebert PC. Transfusion thresholds and other strategies for guiding allogeneic red blood cell transfusion. Cochrane Database Syst Rev (2012) 4:CD002042. doi: 10.1002/14651858

8. MCintyre LA, Fergusson DA, Hutchinson JS, Pagliarello G, Marshall JC, Yetisir E, et al. Effect of a liberal versus restrictive transfusion strategy on mortality in patients with moderate to severe head injury. Neurocrit Care (2006) 5:4-9. doi:10.1385/NCC:5:1:4

9. Carson JL, Hill S, Carless P, Hebert P, Henry D. Transfusion triggers: a systematic review of the literature. Transfus Med Rev (2002) 16:187-99. doi:10.1053/ tmrv.2002.33461

10. Fortune JB, Feustel PJ, Saifi J, Stratton HH, Newell JC, Shah DM. Influence of hematocrit on cardiopulmonary function after acute hemorrhage. J Trauma (1987) 27:243-9. doi:10.1097/00005373-198703000-00003

11. Topley E, Clarke R. The anemia of trauma. Blood (1956) 11:357-69.

12. Robertson CS, Hannay HJ, Yamal JM, Gopinath S, Goodman JC, Tilley BC, et al. Effect of erythropoietin and transfusion threshold on neurological recovery after traumatic brain injury: a randomized clinical trial. JAMA (2012) 312:36-47. doi:10.1001/jama.2014.6490

13. Hare GM, Mazer CD, Hutchinson JS, Mclaren AT, Liu E, Rassouli A, et al. Severe hemodilutional anemia increases cerebral tissue injury following acute neurotrauma.JApplPhysiol(2007) 103:1021-9.doi:10.1152/japplphysiol.01315.2006

14. Valadka AB, Gopinath SP, Contant CF, Uzura M, Robertson CS. Relationship of brain tissue PO2 to outcome after severe head injury. Crit Care Med (1998) 26:1576-81. doi:10.1097/00003246-199809000-00029

15. Johnston AJ, Gupta AK. Advanced monitoring in the neurology intensive care unit: microdialysis. Curr Opin Crit Care (2002) 8:121-7. doi:10.1097/00075198-200204000-00006 manuscript preparation. SD, surgical procedures and data collection. DP and OR, intracardiac echography and transeptal catheterization. LG, manuscript preparation. $A B$, statistical analysis. $\mathrm{JP}, \mathrm{RB}$ and JF, data interpretation and manuscript preparation.

\section{ACKNOWLEDGMENTS}

This work was supported by the Australian Defence Health Foundation 2012 Research grant - ADHREC number: 2012/ 1175375. JF acknowledges the support provided by Queensland Health Research Fellowship.

16. Stiefel MF, Tomita Y, Marmarou A. Secondary ischemia impairing the restoration of ion homeostasis following traumatic brain injury. J Neurosurg (2005) 103:707-14. doi:10.3171/jns.2005.103.4.0707

17. Bardt TF, Unterberg AW, Hartl R, Kiening KL, Schneider GH, Lanksch WR. Monitoring of brain tissue PO2 in traumatic brain injury: effect of cerebral hypoxia on outcome. Acta Neurochir Suppl (1998) 71:153-6.

18. Stocchetti N, Chieregato A, De Marchi M, Croci M, Benti R, Grimoldi N. High cerebral perfusion pressure improves low values of local brain tissue $\mathrm{O} 2$ tension $\left(\mathrm{PtiO}_{2}\right)$ in focal lesions. Acta Neurochir Suppl (1998) 71:162-5.

19. Stiefel MF, Spiotta A, Gracias VH, Garuffe AM, Guillamondegui O, MaloneyWilensky E, et al. Reduced mortality rate in patients with severe traumatic brain injury treated with brain tissue oxygen monitoring. J Neurosurg (2005) 103:805-11. doi:10.3171/jns.2005.103.5.0805

20. Narotam PK, Morrison JF, Nathoo N. Brain tissue oxygen monitoring in traumatic brain injury and major trauma: outcome analysis of a brain tissue oxygen-directed therapy. J Neurosurg (2009) 111:672-82. doi:10.3171/2009.4.JNS081150

21. Peerdeman SM, Girber AR, Vandertop WP. Cerebral microdialysis as a new tool for neurometabolic monitoring. Intensive Care Med (2000) 26:662-9. doi:10.1007/s001340051230

22. Bellapart J, Boots R, Fraser J. Physiopathology of anemia and transfusion thresholds in isolated head injury. J Trauma Acute Care Surg (2012) 73. 997-1005. doi:10.1097/TA.0b013e318265cede

23. Maybauer DM, Maybauer MO, Traber LD, Westphal M, Nakano YY, Enkhbaatar P, et al. Effects of severe smoke inhalation injury and septic shock on global hemodynamics and microvascular blood flow in sheep. Shock (2006) 26:489-95. doi:10.1097/01.shk.0000230300.78515.ed

24. Videtta W, Villarejo F, Cohen M, Domeniconi G, Santa Cruz R, Pinillos O, et al. Effects of positive end-expiratory pressure on intracranial pressure and cerebral perfusion pressure. Acta Neurochir Suppl (2002) 81:93-7.

25. Simonova G, Tung JP, Fraser JF, Do HL, Staib A, Chew MS, et al. A comprehensive ovine model of blood transfusion. Vox Sang (2014) 106:153-60. doi:10.1111/vox.12076

26. Hodgetts VE. The dynamic red cell storage function of the spleen in sheep. III. Relationship to determination of blood volume, total red cell volume, and plasma volume. Aust J Exp Biol Med Sci (1961) 39:187-95. doi:10.1038/icb.1961.19

27. Bellapart J, Dunster KR, Diab S, Platts DG, Raffel C, Gabrielian L, et al. Intracardiac echocardiography guided transeptal catheter injection of microspheres for assessment of cerebral microcirculation in experimental models. Cardiol Res Pract (2013) 2013:595838. doi:10.1155/2013/595838

28. Hodeigee D, De Pauw M, Eechaute W, Weyne J, Heyndrickx GR. On the validity of blood flow measurement using colored microspheres. Am J Physiol (1999) 276:H1150-8.

29. Liaw PC. Endogenous protein C activation in patients with severe sepsis. Crit Care Med (2004) 32:S214-8. doi:10.1097/01.CCM.0000126125.79861.D3

30. Booke M, Westphal M, Hinder F, Traber LD, Traber DL. Cerebral blood flow is not altered in sheep with Pseudomonas aeruginosa sepsis treated with norepinephrine or nitric oxide synthase inhibition. Anesth Analg (2003) 96:1122-8.

31. Prinzen FW, Bassingthwaighte JB. Blood flow distributions by microsphere deposition methods. Cardiovasc Res (2000) 45:13-21. doi:10.1016/ S0008-6363(99)00252-7 
32. Hakkinen JP, Miller MW, Smith AH, Knight DR. Measurement of organ blood flow with coloured microspheres in the rat. Cardiovasc Res (1995) 29:74-9. doi:10.1016/S0008-6363(96)88549-X

33. Itoh T, Satou T, Nishida S, Tsubaki M, Hashimoto S, Ito H. Expression of amyloid precursor protein after rat traumatic brain injury. Neurol Res (2009) 31:103-9. doi:10.1179/016164108X323771

34. Bellapart J, Cuthbertson K, Skerman J, Dunster K, Diab S, Platts D, et al. Colour coded microspheres and histological analysis for cerebral mapping: an experimental model. J Neurol Res (2014) 4:7-14.

35. SlaterG, VladeckBC,Bassin R, Brown RS, ShoemakerWC. Sequential changes in cerebralblood flow and distribution offlow within the brain duringhemorrhagic shock. Ann Surg (1975) 181:1-4. doi:10.1097/00000658-197501000-00001

36. Kovach AG. Cerebral circulation in hypoxia and ischemia. Prog Clin Biol Res (1988) 264:147-58.

37. Kovach AG, Sandor P. Cerebral blood flow and brain function during hypotension and shock. Annu Rev Physiol (1976) 38:571-96. doi:10.1146/annurev. ph.38.030176.003035
38. Ainslie PN, Smith KJ. Integrated human physiology: breathing, blood pressure and blood flow to the brain. J Physiol (2011) 589:2917. doi:10.1113/ jphysiol.2011.211292

39. Brown M, Wittwer C. Flow Cytometry, principles and clinical applications in hematology. Clin Chem (2000) 46:1221-9.

Conflict of Interest Statement: The authors declare that the research was conducted in the absence of any commercial or financial relationships that could be construed as a potential conflict of interest.

Copyright (c) 2016 Bellapart, Cuthbertson, Dunster, Diab, Platts, Raffel, Gabrielian, Barnett, Paratz, Boots and Fraser. This is an open-access article distributed under the terms of the Creative Commons Attribution License (CC BY). The use, distribution or reproduction in other forums is permitted, provided the original author(s) or licensor are credited and that the original publication in this journal is cited, in accordance with accepted academic practice. No use, distribution or reproduction is permitted which does not comply with these terms. 